\title{
Improving Handwashing Promotion and Practice in Emergency Contexts: Evaluating Two Novel Approaches in Nduta Camp, Tanzania
}

\section{Foyeke Tolani ${ }^{1 *}$, Betty Ojeny ${ }^{1}$, Michelle Ping-Lee D'Amico ${ }^{2}$, Loveness Raphael $^{1}$, Liz Barker ${ }^{3}$ and Jamae Fontain Morris ${ }^{2}$}

${ }^{1}$ Oxfam, Oxford, UK

${ }^{2}$ Georgia State University, Atlanta, Georgia, USA

${ }^{3}$ The Behavioural Architects, UK

*Corresponding Author: Foyeke Tolani, Oxfam, Oxford, UK.
Received: September 03, 2020

Published: October 28, 2020

(C) All rights are reserved by Foyeke Tolani., et al.

\section{Abstract}

Background: Handwashing with soap can disrupt the transmission of diarrhea-causing pathogens, a major cause of morbidity in emergency settings. However, evidence that traditional hygiene promotion activities drive sustained increases in handwashing is weak. We aimed to test: 1) an improved handwashing station and whether it increased handwashing and 2) if pairing improved stations with a behavioral intervention based on emotional drivers further increased handwashing.

Methods: We conducted a three-arm clustered randomized controlled trial in Nduta refugee camp, Tanzania, enrolling all households in each intervention arm using systematic sampling. One arm was given access to the Promotion and Practice Handwashing Kit (PPHWK), a kit designed by Oxfam and partners. The second arm had access to the PPHWK and a behavioral intervention-Mum's Magic Hands (MMH), a handwashing promotion strategy based on emotive drivers, with mothers and female carers as primary target group. The third arm was the control group. Baseline and endline data were collected using surveys, focus group discussions (FGDs), structured and qualitative observations.

Results: At endline, all intervention households were more likely to note the importance of handwashing. In structured observations, persons from PPHWK+MMH households practiced handwashing more consistently 94.3\%, compared with 78.0\% in PPHWK only and $69.6 \%$ in control. PPHWK+MMH households self-reported significantly lower rates of diarrhea at endline than baseline $\mathrm{p}=$ 0.025. FGD participants preferred the PPHWK over alternative handwashing stations (tippy taps), citing good design, durability, and ease of use. All participants exposed to MMH considered it effective, with a reported increase in handwashing with soap, particularly among children.

Conclusion: We found substantial improvements in both reported and observed handwashing with soap associated with PPHWK access, especially when paired with MMH. Pairing an improved handwashing station with innovative promotion strategies may significantly improve handwashing and subsequently reduce morbidity among refugee populations. Feedback on the PPHWK and MMH were used to develop a new PPHWK prototype and improve on MMH approach of targeting mothers and other household members. Keywords: Emergency Contexts; Emotional Drivers; Environmental Cues; Handwashing Stations; Handwashing with Soap; WASH; Refugee Camp; Tanzania; Mothers in Refugee Context

\section{Introduction}

Diarrhea is a leading cause of morbidity in refugee settings $[1,2]$. Handwashing with soap can disrupt the transmission of diarrhea-causing pathogens [2-5], reportedly reducing the risk of diarrhea by anything from $31 \%$ to $48 \%$ [6-9]. Handwashing technologies and their characteristics play a potentially important role in enabling or inhibiting regular handwashing at key times $[1,10]$. Current low-cost handwashing solutions available in refugee set- 
tings are often poorly constructed, difficult to use (especially for young children, the elderly, and disabled persons), lack adequate drainage, and require frequent refilling with water [7]. Poor-quality handwashing facilities can inhibit regular, habitual handwashing with soap at key times, including after latrine use and before feeding young children. In Bangladesh Hulland., et al. (2013) through a series of behavioral trials, found that cost, durability, storage capacity, ease of use, and maintenance influenced users' preferences for handwashing technologies [1]. Similarly, in Cambodia Jenkins., et al. (2013) found that existing technologies made handwashing awkward and time-consuming and that low-cost handwashing technologies that improve ease and convenience may encourage increased handwashing behaviors [10].

Hygiene promotion, paired with the provision of soap, is accepted as one of the most cost-effective methods for disease prevention. However, simply providing access to soap and standard handwashing promotion does not necessarily translate into sustained increases in handwashing [11-13]. There is a need to build on and test alternative solutions. Recent studies have demonstrated the effectiveness of strategies that pair the provision of soap with approaches that use emotional drivers $[12,14,15]$ and environmental cues $[1,10]$ to build the habit of handwashing with soap.

Standard handwashing promotion strategies, which have demonstrated limited long-term increases in practice, are frequently informed by social cognitive models that focus on changing health beliefs and the acquisition of knowledge as a mechanism for behavior change [12,16]. In contrast, Biran., et al. (2014) tested an intervention based on emotional drivers including nurture, disgust, affiliation, and status, rather than knowledge, to increase handwashing with soap in a rural community in India [12]. After the intervention, the proportion of the population handwashing with soap at key times increased substantially, from $2 \%$ at baseline to $29 \%$ twelve months post-intervention. The potential utility of interventions that use emotional drivers to increase behavior change has been highlighted elsewhere $[14,15,17]$. These findings are promising and, when paired with strategies that leverage environmental cues and nudges to influence handwashing (i.e. ready access to low-cost, user-friendly handwashing stations and visuals or text-based slogans) may demonstrate an even greater increase in handwashing with soap practice. Deploying a robust approach that incorporated both emotional drivers and environmental cues, the study, part of an ongoing effort to improve handwashing with soap practice in refugee settings, sought to evaluate whether the provision of improved handwashing technologies with alternative handwashing promotion strategies increased handwashing with soap in Nduta Refugee Camp, Tanzania.

\section{Nduta camp, Tanzania}

As of October 2017, Nduta camp was home to 125,546 refugees [18] and Oxfam, through the Burundi Refugee Response (BRR), has been providing water, sanitation, and hygiene promotion (WASH) services, food security and livelihoods projects within the camp and surrounding host communities. The WASH approach included water infrastructure development, latrine construction, and hygiene promotion (for more information on Oxfam's work in Nduta, see https://www.oxfam.org/en/burundi/nduta-refugee-campreopens-welcome-thousands-burundian-refugees).

\section{Description of intervention}

Oxfam worked with a multi-disciplinary team, consisting of WASH specialists, product design and manufacturing design specialists, a behavior change expert, and humanitarian logisticians to develop the Promotion and Practice Handwashing Kit (PPHWK), a user-friendly, robust handwashing station that can be easily set up near latrines in emergency settings. The kit comprises a base superstructure, water storage tank, water-conserving dispenser (the Oxfam Handywash tap), handwashing tray with provision for soap placement, drainage pipe, and a mirror.

Coupled with the PPHWK, the intervention program used Mum's Magic Hands (MMH), a hygiene promotion strategy developed by Oxfam and Unilever's Lifebuoy Soap. MMH draws on the concepts of nurture and affiliation, which are found to be effective emotional drivers for caregivers [19], to motivate mothers to wash their hands at key times, before contact with food and after contact with feces. To accomplish this, MMH focuses on the positive role a mother's hands can play in children's lives and reinforces the message that those same hands, if not kept clean, can play a role in transmitting disease. The strategy incorporates storytelling, interactive demonstrations, and innovative promotional materials (posters and stickers) to encourage handwashing among mothers, female carers and the rest of the family. The intervention lasts for 8 weeks and includes soap distribution to promote handwashing at the household level. The version of MMH employed in this intervention employed images of mothers from different cultural backgrounds in storyboards and other promotional material. (For 
additional information see https://policy-practice.oxfam.org.uk/ our-work/water-sanitation-and-hygiene/mums-magic-hands).

\section{Methodology}

Sampling

Nduta refugee camp had a total population of 126,740 in July 2017 , comprising 25,372 households. The camp was divided into 21 zones, with approximately 30 villages per zone, and was organized into two administrative levels of zones and villages. We selected three camp zones at baseline, one for each intervention arm, considering existing latrine status, access to water, status of existing handwashing facilities, and proximity to other zones. Zones 16,18 , and 21 were chosen. Selected zones did not share physical borders, to eliminate any spillover effect. Villages with 10-15 communal latrine areas were eligible for inclusion in the study, and we randomly selected two villages in each zone which met that requirement.

At baseline, we used systematic sampling to enroll study households: 77 in intervention arm 1, 91 in arm 2, and 81 in the control group. Enumerators used the camp map to identify the boundaries of each village and, beginning with households closest to the main road/entry point, enumerated every $7^{\text {th }}$ household. The primary female caregiver was approached for inclusion in the study. Enumerators detailed all aspects of the study using an informed consent document, and verbal informed consent was collected.

\section{Study design}

We designed a clustered randomized controlled trial (RCT), assigning intervention arms as follows (Diagram 1):

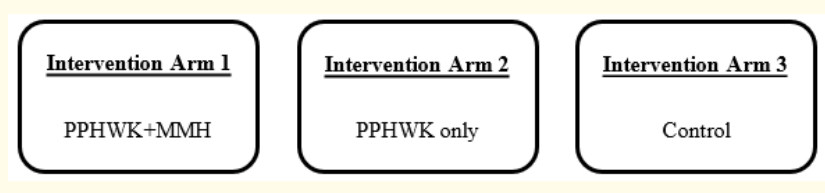

Diagram 1: Intervention arms.

Intervention arm 1: PPHWK plus behavioral intervention (PPHWK+MMH)

- $\quad$ Tailored WASH training sessions, using Mum's Magic Hands

- $\quad 16$ PPHWK handwashing stations installed near latrines in study villages, including a nudge message placed on each station consisting of a slogan and visual, drawing on the concept of nurture and affiliation to complement the $\mathrm{MMH}$ program.
Intervention arm 2: PPHWK only

- $\quad$ Standard WASH training sessions

- 16 PPHWK handwashing stations installed, including a nudge message placed on each station, consisting of a slogan and image leveraging the concept of disgust, to complement the standard WASH training sessions.

\section{Intervention arm 3: Control}

- $\quad$ Standard WASH training sessions

- 16 existing handwashing stations used in the camp (tippy taps, consisting of suspended jerrycans filled with soapy water and tipped using a foot control).

\section{Data collection}

We implemented a pilot project between February and May 2018, including a 2-week evaluation period. We used both quantitative and qualitative data collection methods. Data collection tools (questionnaires and discussion guides) were modeled after formative research tools used in an earlier intervention in Nepal, with some modifications to suit the context [19].

\section{Household surveys}

We targeted all adult heads of household enrolled in the study for the household survey. Enumerators approached all study households in each intervention arm. Where a household head was not found, the enumerator made two more attempts to collect the survey data. The household survey was designed to gather information on demographics, access to handwashing information, beliefs about key times for handwashing, and any self-reported diarrhea in the household in the preceding 14 days. We collected survey data using Mobenzi mobile technology. The survey sample size was calculated based on a 5\% margin of error and $95 \%$ confidence level calculated at baseline. The household survey sample size decreased at endline as a result of the Burundian Refugee Voluntary Repatriation Operation [20], a government-backed operation to repatriate Burundian refugees to their home country beginning in September 2017. As of July 2018, more than 26,534 residents of Nduta camp had been repatriated to Burundi.

\section{Structured observations}

Structured observations were conducted to further understand community handwashing practice and assess whether hands were being washed properly (i.e. with water and soap). Observations were conducted across all intervention arms of the study. Enumerators observed handwashing stations and documented handwashing practice, soap availability, and handwashing at key times. 
All structured observations were conducted from 6-9am over the course of 7 days, when every household member was likely to visit the communal latrine at least once during the 3-hour period. More than 120 hours of structured observation data were collected. Additionally, to limit the possibility of the Hawthorne Effect, when people's behavior is influenced by knowing that they are being watched, enumerators were discreet during the structured observations (i.e. sat at a distance, beside a building or tree).

\section{Qualitative observations}

We conducted qualitative observations to detail broader user experiences. We recorded information on the general age of the user, handwashing practice, soap availability and water at the handwashing station, and any observed challenges experienced while handwashing. Handwashing stations in selected villages were observed for 1 hour per day from 8-9am for each intervention arm, for a period of 4 days. Over 24 total hours of qualitative observation data were collected.

\section{Focus group discussions and spidergrams}

We used convenience sampling to identify 10 - 15 participants for female and male focus group discussions (FGDs) respectively. FGDs were conducted separately for men and women in each intervention arm (1 FGD each) to discuss the PPHWK (and MMH), and a separate FGD was conducted in each intervention arm with women only to discuss MMH. Thus, a total of 9 FGDs was conducted across all intervention arms, 2 with women and 1 with men for each arm. All FGDs were audio recorded, with consent from participants.

To document additional perceptions on existing and new handwashing facilities, we carried out a spidergram activity (a tool to map and link ideas associated with a primary concept or topic) with FGD participants after the discussion ended. Male and female participants in each intervention arm were asked to score handwashing stations according to several key aspects: ease of maintenance, durability, motivation, ease of use, and aesthetic value. Key aspects were scored from 1 to 5 , with 1 being lowest and 5 highest (see results section for example spidergram).

\section{Key informant interviews}

Twenty-minute key informant interviews (KIIs) were carried out with 3 Oxfam staff members and 1 health volunteer to get their overall feedback on PPHWK, including on ease of installation compared with existing handwashing stations (e.g. tippy taps). All individuals interviewed participated in the installation of the handwashing kit.

\section{Data analysis}

We used R (Version 3.4.4) and RStudio (Version 1.1.442) for household survey data management and analysis. We calculated descriptive statistics for all responses to the household survey, with comparisons by intervention group when relevant. For count data, we calculated frequencies and proportions. For continuous data, we calculated mean and standard DEVIATION where there was evidence of a normal distribution, and median and interquartile range where there was an apparent violation of normality.

We calculated inferential statistics of household survey data as follows. For count data, we conducted Pearson's chi-squared test to compare expected frequencies versus what was observed; when expected cell size was less than 5, we used Fisher's exact test. We used one-way analysis of variance to compare differences in means by intervention group and the Kruskal-Wallis rank sum test to compare global differences in medians by intervention group. We used a significance level of alpha $=0.05$ for all tests in this study. We also used the Welch Two-Sample T test to compare endline and baseline household recall of diarrhea by intervention group.

We transcribed qualitative data from audio files and field notes and translated them into English from Kiswahili and Kirundi. We reviewed data using grounded theory, an inductive approach where study data inform the central patterns and themes considered. We uploaded transcriptions to NVivo (Version 11.4.3) for coding.

\section{Ethics}

The study protocol and instruments were reviewed from an ethical standpoint by an ethical consultant from the Institute of Development Studies (IDS), University of Sussex, Brighton, UK (the implementing organization does not have an ethical approval board but it followed all ethical guidance given by the donor, $\mathrm{Hu}$ manitarian Innovation Fund - HIF). We also received approval to carry out the study from the Office of the United Nations High Commissioner for Refugees (UNHCR), the organization in charge of the camp, as part of the ongoing refugee response, and from the Office of the President on behalf of the Government of Tanzania.

Enumerators obtained verbal informed consent from each adult head of household (the respondent) and recorded their consent on paper and in the electronic data collection form. 


\section{Results}

Household demographic information

At endline a total of 184 respondents completed the household survey across the three intervention arms. We collected data only from the female or male head of household. Most household survey respondents were female, representing between $84.3 \%$ and $98.3 \%$ of participants, and had completed primary-level education. More than half of participants reported an average household size of approximately 4 persons, including 1 child $<5$ years of age, and approximately $13 \%$ of all households reported having at least 1 household member with a disability. Almost all households participating in the household survey, $>97 \%$ across all intervention groups, had lived in the camp for more than 1 year (Table 1 ).
Handwashing knowledge, attitudes, and practice

At endline, more of the households that received the intervention reported receiving information on handwashing since arriving at the camp i.e. $>98 \%$ across all intervention households, compared with control households (88.3\%). These differences were statistically significant, $p=0.002$. A similar proportion of respondents across all three intervention arms $(\geq 94 \%)$ stated that the handwashing information they received while at the camp was adequate. At endline, all intervention households, both PPHWK only and PPHWK+MMH, were more likely to note the importance of handwashing at 4 key timepoints, with these differences being statistically significant (Table 2).

\begin{tabular}{|c|c|c|c|c|}
\hline & \multicolumn{3}{|c|}{ Intervention Group } & \multirow[t]{2}{*}{ P-value } \\
\hline & $\begin{array}{c}\text { Control } \\
\text { (Zone 16) } \\
\mathrm{n}=\mathbf{6 0}(32.6 \%)\end{array}$ & $\begin{array}{c}\text { PPHWK only } \\
\text { (Zone 18) } \\
n=70(38 \%)\end{array}$ & $\begin{array}{c}\text { PPHWK+MMH } \\
\text { (Zone 21) } \\
\mathrm{n}=54(29.3 \%)\end{array}$ & \\
\hline $\begin{array}{l}\text { Age, in years } \\
\text { Median (inter-quartile range) }\end{array}$ & $27.5(9.25)$ & $25.0(15.00)$ & $32.0(18.75)$ & 0.007 \\
\hline $\begin{array}{l}\text { Observed gender* } \\
\text { Female } \\
\text { Male }\end{array}$ & $\begin{array}{c}59(98.3 \%) \\
1(1.7 \%) \\
\end{array}$ & $\begin{array}{l}59(84.3 \%) \\
11(15.7 \%) \\
\end{array}$ & $\begin{array}{c}47(87.0 \%) \\
7(13.0 \%)\end{array}$ & 0.024 \\
\hline $\begin{array}{l}\text { Highest level of education }^{0} \\
\text { Secondary } \\
\text { Primary } \\
\text { None } \\
\text { Other }\end{array}$ & $\begin{array}{c}0 \\
33(55 \%) \\
26(43.33 \%) \\
1(1.67 \%) \\
\end{array}$ & $\begin{array}{c}9(12.86 \%) \\
42(60 \%) \\
19(27.14 \%) \\
0\end{array}$ & $\begin{array}{c}3(5.56 \%) \\
40(74.07 \%) \\
11(20.37 \%) \\
0\end{array}$ & 0.003 \\
\hline $\begin{array}{l}\text { Marital status }^{0} \\
\text { Unmarried } \\
\text { Divorced } \\
\text { Married } \\
\text { Separated } \\
\text { Single parent } \\
\text { Widowed }\end{array}$ & $\begin{array}{c}1(1.7 \%) \\
1(1.7 \%) \\
42(70.0 \%) \\
2(3.3 \%) \\
7(11.7 \%) \\
7(11.7 \%) \\
\end{array}$ & $\begin{array}{c}11(15.7 \%) \\
0 \\
43(61.4 \%) \\
1(1.4 \%) \\
11(15.7 \%) \\
4(5.7 \%) \\
\end{array}$ & $\begin{array}{c}2(3.7 \%) \\
0 \\
34(63 \%) \\
2(3.7 \%) \\
7(13.0 \%) \\
9(16.7 \%) \\
\end{array}$ & 0.061 \\
\hline $\begin{array}{l}\text { Number of individuals in household } \\
\text { Mean (standard deviation) }\end{array}$ & $4.75(1.97)$ & $4.08(2.01)$ & $4.04(1.88)$ & 0.071 \\
\hline $\begin{array}{l}\text { Number of children }<\mathbf{5} \text { years of age in household } \\
\text { Mean (standard deviation) }\end{array}$ & $1.37(0.80)$ & $0.94(0.80)$ & $0.96(0.87)$ & 0.006 \\
\hline $\begin{array}{l}\text { Person with disability in household } \\
\text { No } \\
\text { Yes }\end{array}$ & $\begin{array}{l}51(85 \%) \\
9(15 \%)\end{array}$ & $\begin{array}{l}58(82.9 \%) \\
12(17.1 \%) \\
\end{array}$ & $\begin{array}{c}47(87 \%) \\
7(13 \%)\end{array}$ & 0.812 \\
\hline $\begin{array}{l}\text { Length of time spent in camp } \\
6 \text { months- } 1 \text { year } \\
\text { More than } 1 \text { year }\end{array}$ & $\begin{array}{c}0 \\
60(100 \%)\end{array}$ & $\begin{array}{c}2(2.86 \%) \\
68(97.14 \%)\end{array}$ & $\begin{array}{c}0 \\
54(100 \%)\end{array}$ & 0.333 \\
\hline
\end{tabular}

Table 1: Demographic information for household members surveyed by intervention group.

§: Kruskal-Wallis rank sum test used.

*: Chi-squared test used.

:: Fisher's exact test used because at least some cells had expected frequencies of $<5$.

†: One-way analysis of variance used. 


\begin{tabular}{|c|c|c|c|c|}
\hline \multirow[t]{2}{*}{ At Baseline } & \multicolumn{3}{|c|}{ Intervention Group } & \multirow[t]{2}{*}{ P-value } \\
\hline & $\begin{array}{c}\text { Control } \\
\text { (Zone 16) } \\
n=135\end{array}$ & $\begin{array}{c}\text { PPHWK only } \\
\text { (Zone 18) } \\
\text { n=136 }\end{array}$ & $\begin{array}{c}\text { PPHWK+ MMH } \\
\text { (Zone 21) } \\
\text { n = 102 } \\
\end{array}$ & \\
\hline $\begin{array}{l}\text { Before eating }^{x} \\
\text { No } \\
\text { Yes }\end{array}$ & $\begin{array}{l}46(34.1 \%) \\
89(65.9 \%)\end{array}$ & $\begin{array}{c}28(20.1 \%) \\
108(79.4 \%)\end{array}$ & $\begin{array}{l}21(20.1 \%) \\
81(79.4 \%)\end{array}$ & $0.016^{*}$ \\
\hline $\begin{array}{l}\text { Before cooking } \\
\text { No } \\
\text { Yes }\end{array}$ & $\begin{array}{c}107(79.3 \%) \\
28(20.7 \%)\end{array}$ & $\begin{array}{c}110(80.9 \%) \\
26(19.1 \%)\end{array}$ & $\begin{array}{l}80(78.4 \%) \\
22(21.6 \%) \\
\end{array}$ & 0.890 \\
\hline $\begin{array}{l}\text { Before feeding baby } \\
\text { No } \\
\text { Yes }\end{array}$ & $\begin{array}{c}102(75.6 \%) \\
33(24.4 \%)\end{array}$ & $\begin{array}{c}102(75.0 \%) \\
34(25.0 \%)\end{array}$ & $\begin{array}{l}79(77.4 \%) \\
23(22.6 \%) \\
\end{array}$ & 0.904 \\
\hline $\begin{array}{l}\text { After using a latrine }^{\mathrm{x}} \\
\text { No } \\
\text { Yes }\end{array}$ & $\begin{array}{l}40(29.6 \%) \\
95(70.4 \%)\end{array}$ & $\begin{array}{c}19(14.0 \%) \\
117(86.0 \%)\end{array}$ & $\begin{array}{l}17(16.7 \%) \\
86(83.3 \%) \\
\end{array}$ & $0.003^{*}$ \\
\hline At Endline & & Intervention & & P-value \\
\hline & $\begin{array}{c}\text { Control } \\
\text { (Zone 16) } \\
n=60 \\
\end{array}$ & $\begin{array}{c}\text { PPHWK only } \\
\text { (Zone 18) } \\
\text { n= } 70\end{array}$ & $\begin{array}{c}\text { PPHWK+ MMH } \\
\text { (Zone 21) } \\
\text { n = 54 }\end{array}$ & \\
\hline $\begin{array}{l}\text { Before eating } \\
\text { No } \\
\text { Yes }\end{array}$ & $\begin{array}{c}9(15.0 \%) \\
51(85.0 \%) \\
\end{array}$ & $\begin{array}{c}0 \\
70(100.0 \%) \\
\end{array}$ & $\begin{array}{c}2(3.7 \%) \\
52(96.3 \%)\end{array}$ & $<0.001^{*}$ \\
\hline $\begin{array}{l}\text { Before cooking }^{\mathrm{x}} \\
\text { No } \\
\text { Yes }\end{array}$ & $\begin{array}{l}26(43.3 \%) \\
34(56.7 \%) \\
\end{array}$ & $\begin{array}{l}16(22.9 \%) \\
54(77.1 \%) \\
\end{array}$ & $\begin{array}{l}13(24.1 \%) \\
41(75.9 \%) \\
\end{array}$ & $0.021^{*}$ \\
\hline $\begin{array}{l}\text { Before feeding baby } \\
\text { No } \\
\text { Yes }\end{array}$ & $\begin{array}{l}26(43.3 \%) \\
34(56.7 \%) \\
\end{array}$ & $\begin{array}{l}15(21.4 \%) \\
55(78.6 \%) \\
\end{array}$ & $\begin{array}{l}18(33.3 \%) \\
36(66.7 \%) \\
\end{array}$ & $0.028^{*}$ \\
\hline $\begin{array}{l}\text { After using a latrine } \\
\text { No } \\
\text { Yes }\end{array}$ & $\begin{array}{c}6(10.0 \%) \\
54(90.0 \%)\end{array}$ & $\begin{array}{c}3(4.3 \%) \\
67(95.7 \%)\end{array}$ & $\begin{array}{c}0(0.0 \%) \\
54(100.0 \%)\end{array}$ & $0.036^{*}$ \\
\hline
\end{tabular}

Table 2: Important times for handwashing by intervention group at baseline and endline.

f: Fisher's exact test used because at least some cells had expected frequencies of $<5$.

x: Pearson's chi-squared test used.

${ }^{*}$ : Statistically significant at alpha $=0.05$.

While a similar proportion of respondents across groups at endline noted the importance of handwashing with soap for the prevention of diarrhea ( $\geq 59 \%$ ) and illness ( $\geq 90 \%)$, respondents in both the control group (41.7\%) and PPHWK only group (28.6\%) were more likely to report handwashing with only water when compared with the intervention group who received both MMH and the PPHWK (14.8\%). Differences were statistically significant, $\mathrm{p}=0.007$ (Table 3).

\begin{tabular}{|l|c|c|c|c|}
\hline & \multicolumn{3}{|c|}{ Intervention Group } & P-value \\
\hline & $\begin{array}{c}\text { Control } \\
\text { (Zone 16) } \\
\mathbf{n = 6 0}\end{array}$ & $\begin{array}{c}\text { PPHWK only } \\
\text { (Zone 18) }\end{array}$ & $\begin{array}{c}\text { PPHWK+ MMH } \\
\text { (Zone 21) }\end{array}$ & \\
\hline No & $35(58.3 \%)$ & $50(71.4 \%)$ & $46(85.2 \%)$ & $0.007 *$ \\
Yes & $25(41.7 \%)$ & $20(28.6 \%)$ & $8(14.8 \%)$ & \\
\hline
\end{tabular}

Table 3: Water-only handwashing by intervention group at endline.

x: Pearson's chi-squared test used.

$*$ : Statistically significant at alpha $=0.05$ level. 


\section{Diarrhea recall}

We asked respondents at baseline and endline whether anyone in their household had suffered from diarrhea in the previous 14 days. Though fewer respondents in the PPHWK+MMH group $(16.7 \%)$ reported any household diarrhea in the preceding 2-week period compared with control (23.3\%) and PPHWK only (27.1\%) households at endline, differences were not statistically significant, $\mathrm{p}=0.38$. However, $\mathrm{PPHWK}+\mathrm{MMH}$ households did report significantly less diarrhea at endline than at baseline, $\mathrm{p}=0.025$. Though there were also decreases in self-reported diarrhea for the other 2 groups, ranging between $6 \%$ and $10 \%$, differences were not statistically significant (Table 4).

\section{Structured observations}

At endline, we had observed a total of 938 handwashing events across all intervention arms. During observations, members of households who received both the PPHWK and MMH were significantly more likely to practice handwashing consistently, $\mathrm{p}<$ .001. We observed more persons from PPHWK+MMH households engaging in handwashing during the observation period than persons from PPHWK only and control households - 94.3\%, compared with $78.0 \%$ and $69.6 \%$ respectively (Table 5).

\begin{tabular}{|l|c|c|c|}
\hline & \multicolumn{2}{|c|}{ Timepoint } & P-value \\
\hline & Baseline & Endline & \\
\hline Control (Zone 16) & $34.1 \%$ & $23.3 \%$ & 0.12 \\
\hline PPHWK only (Zone 18) & $33.8 \%$ & $27.1 \%$ & 0.322 \\
\hline PPHWK+MMH (Zone 21) & $32.4 \%$ & $16.7 \%$ & $0.025^{*}$ \\
\hline
\end{tabular}

Table 4: Households reporting diarrhea in the previous 14 days at baseline and endline.

§: Welch two-sample t-test used.

$*$ : Statistically significant at alpha $=0.05$.

\begin{tabular}{|l|c|c|c|c|}
\hline & \multicolumn{3}{|c|}{ Intervention Group } & P-value \\
\hline & $\begin{array}{c}\text { Control (Zone 16) } \\
\mathbf{n = 3 4 2}\end{array}$ & $\begin{array}{c}\text { PPHWK only (Zone 18) } \\
\mathbf{n = 2 2 7}\end{array}$ & $\begin{array}{c}\text { PPHWK+MMH (Zone 21) } \\
\mathbf{n}=\mathbf{3 6 9}\end{array}$ & $<.001^{*}$ \\
\hline Did person wash hands & & & $21(5.69)$ \\
No & $104(30.4 \%)$ & $50(22.0 \%)$ & $348(94.31 \%)$ & 0.164 \\
Yes & $238(69.6 \%)$ & $177(77.9 \%)$ & $366(99.19 \%)$ & $3(0.81 \%)$ \\
\hline Washing behavior & & & \\
Soap and water & $333(97.37 \%)$ & $224(98.68 \%)$ & $3(1.32 \%)$ & \\
Water only & $9(2.63 \%)$ & & \\
\hline
\end{tabular}

Table 5: Structured observations of handwashing at endline.

x: Pearson's chi-squared test used.

f: Fisher's exact test used because at least some cells had expected frequencies of $<5$.

*: Statistically significant at alpha $=0.05$.

\section{Qualitative observations}

We had observed a total of 71 persons at endline: 27 from PPHWK+MMH households, 24 from PPHWK only households, and 20 from control households. Those observed included young children, elderly persons, and one person with a visible physical disability. Of the 27 persons in PPHWK+MMH households observed using the kit, 24 persons of varying ages washed their hands with soap and water and had no observed difficulties using the PPHWK. The 3 persons observed who did not engage in handwashing were all in the same village; the kit's water tank remained empty throughout the observation period. Among PPHWK only households, all per- sons were observed handwashing with soap and water. Only one challenge was noted: an unaccompanied young child, estimated to be $<5$ years of age, had difficulty using the PPHWK because of its height. Although we observed everyone in control households attempting to use the tippy tap after latrine use, more than half of persons (11 of 20) had difficulty using the kit and subsequently discontinued use before washing their hands. Water from the tippy tap spilled onto their clothes or legs, causing them to walk away. All individuals who experienced challenges (11 of 11) were either young children or elderly persons. All handwashing observed during qualitative observations, across all three groups, was associat- 
ed with latrine use. At the time of observations, soap was present at all PPHWKs and soapy water was noted at all tippy taps. Thirteen of 16 PPHWK water tanks were at least half full; of the remaining 3, 1 had no water and 2 were less than quarter full. All tippy taps were at least half full at the time of observation.

\section{Focus group discussions}

Overwhelmingly, participants noted challenges with using tippy taps, particularly for young children and persons with disabilities, because of the height of the handwashing station. Participants noted that often water would spill onto the user's legs. A 33-year-old woman observed, "Sometimes with the tippy tap, water spills onto people's feet, so it would be better if they could find a way to solve this problem." Tippy taps were also described as being less durable and prone to sun damage and breakage. No participant reported a preference for the tippy tap. Another woman (52 years old) noted, "It does not look attractive; we just wash our hands there because there is no alternative".

According to FGD participants, the PPHWK on the other hand was well designed, durable, and easy to use for everyone. "This handwashing facility is very attractive ... and it is very easy to use for younger children and persons with disabilities" (25-year-old woman). Speaking about maintenance of the PPHWK, a male FGD participant (36 years old) asserted, "It is not easy to clean the tippy taps, especially inside the jerrycans. But this new one is very easy to clean outside and inside because you can remove the cover".

Throughout the women only FGDs on $\mathrm{MMH}$, participants described the ways that MMH connected to their lives and their interactions with family; most notably, mothers described how the lessons they had learned related to the way they cared for their children. One mother (53 years old), specifically said: The main message was to take care of our family, especially children, by using magic found in our hands through handwashing, and the message was relevant to me and my family as it reflected a part of our lives here. Also, as a mother, it's my responsibility to take care of my children and encourage them to adopt hygiene behaviors so that they can grow healthy and happy.

Participants noted a number of post-MMH changes in handwashing practice. Most notably, mothers asserted that they not only washed their hands more frequently and at key times but also that they now used water and soap. Reflecting the sentiments of several female participants, another mother (33 years old) focused on the key times for handwashing: "Nowadays, I wash my hands with soap before preparing food, after coming from the latrine, while before the program my handwashing was not frequent".

\section{Spidergrams}

Average scores for both types of handwashing station were compared on several key aspects: ease of maintenance, durability, motivation, ease of use, and aesthetic value (Chart 1). Key aspects were scored from 1 to 5 , with higher scores associated with higher levels of satisfaction. For the tippy tap, average scores ranged between 1 and 2.2, with motivation being the only measure receiving a score above 2 . In contrast, average scores for the PPHWK ranged between 4 and 5 , with only durability receiving a score of less than 5 (as the kits had only been in use for 2 months, users felt they needed more time to assess this aspect, but believed them to be durable).

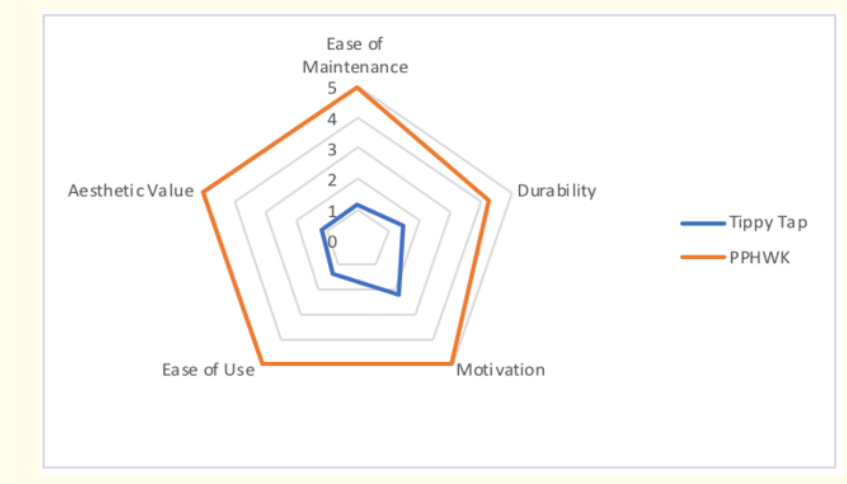

Chart 1: Satisfaction with Key Aspects of PPHWK vs Tippy Taps.

\section{Key informant interviews with installation staff}

All staff interviewed mentioned that they had worked with tippy taps and all considered their installation to be simple, requiring anything between 8 and 30 minutes and no additional technical skills. Compared with the installation process for tippy taps, some interviewees noted that PPHWK installation required a little more concentration, though some said that the process became easier with experience and noted the availability of the installation manual. PPHWK installation was estimated to take around 30 minutes (though for the latest prototype, developed since the study, it has fallen to 6 minutes). Compared with procurement of materials for tippy taps, staff noted that PPHWK procurement was more challenging, as some materials could not be sourced locally. However, 
one participant asserted that PPHWK procurement was easier because all the materials were sourced from a single supplier.

\section{Discussion}

Handwashing with soap is widely recognized as a key strategy for reducing disease transmission; this is particularly true for emergency contexts where overcrowding and poor WASH conditions are common [13]. Traditional knowledge-building handwashing promotion alone has demonstrated limited impact on increasing handwashing with soap practice in these settings $[11,13]$. However, interventions that focus on emotional drivers [12] and/ or environmental cues $[1,10]$ to increase handwashing with soap practice show promise.

We conducted a clustered RCT to evaluate the effectiveness of the PPHWK together with MMH, an innovative set of handwashing promotional materials drawing on emotive drivers, to encourage handwashing with soap practice among refugees in Nduta camp, Tanzania. We collected quantitative and qualitative data to assess: 1) if the provision of improved handwashing stations increased handwashing practice as compared with existing handwashing options, and 2) if pairing the PPHWK with a creative, tailored behavioral intervention (MMH) resulted in an additional increase in handwashing practice.

This study had some important limitations. First, it was designed as a short pilot, and evaluation data were collected approximately only 12 weeks after implementation, thereby limiting our ability to assess whether the PPHWK and MMH training had a sustained, long-term impact on handwashing practice and reported diarrhea rates. This is particularly notable given reported challenges in achieving long-term handwashing behavior change $[11,13]$. Second, while the time period selected for structured observations (6 am - 9 am) successfully captured handwashing events associated with latrine use, in the absence of further observations we cannot assume a similar frequency of handwashing associated with other key events later in the day. Third, over the period of the study repatriation efforts for Burundian refugees supported by the Tanzanian government resulted in a decrease in the broader camp population, and so the number of participants for the evaluation was considerably smaller than the number of participants at baseline. Fourth, with any randomization, baseline imbalances may still occur by virtue of probability; in this analysis, participants in the PPHWK only and PPHWK+MMH intervention arms were better educated than those in the control group, which might have influenced their better knowledge of the importance of handwashing at baseline. Using more than three clusters (zones) in the analysis would have strengthened the study, as there are likely substantial similarities within zones that could have unduly influenced the data analysis. Lastly, to more rigorously assess the impact on handwashing with soap practice associated with MMH only, a fourth treatment arm would have been necessary. Despite these limitations, a number of key findings emerged.

Most significantly, substantial improvements in both reported and observed handwashing with soap practice were associated with PPHWK use and pairing MMH with PPHWK use. PPHWK+MMH households demonstrated the highest levels of handwashing with soap, confirmed through structured observations. This likely explains the significant decrease in self-reported diarrhea from endline to baseline in the PPHWK+MMH arm. Intervention households for PPHWK only and PPHWK+MMH were more likely to recall the key times for handwashing (before eating, before feeding baby, before cooking, and after using the latrine). Group differences were significant.

Participants reported broad access to WASH promotion, and more than $80 \%$ of study households reported access to adequate WASH training since arriving at the camp. Standard handwashing promotion strategies were targeted to the entire camp population. While access does not necessarily translate into sustained behavior change [13], this likely explains several improvements in handwashing knowledge and practice observed in the control group when compared with baseline. Despite access to standard WASH promotion, households in the control group were significantly more likely to report handwashing with water only and were therefore at increased risk of disease transmission.

It is also important to note that households with access to the PPHWK demonstrated higher levels of handwashing knowledge than households exposed to only standard WASH promotion. A greater proportion of PPHWK only households noted each of the four key times for handwashing and demonstrated a better command of steps for safe handwashing when compared with the control group. These findings suggest that creating handwashing options that appeal to the community encourages habitual use and, when paired with WASH promotion strategies, may positively impact the retention, recall, and/or practice of WASH train- 
ing. Previous researchers have noted the impact of handwashing technologies with high levels of user acceptability and feasibility on increasing handwashing practice. However, we have not found any other studies that explore the impact of these technologies on the retention of WASH information, including key times for handwashing and proper handwashing technique. Additional research is warranted.

As with reported handwashing knowledge and practice, differences in observed practice were tiered. Households who received both the PPHWK and MMH training were most frequently observed handwashing, followed by households who received only the PPHWK. Control households were observed handwashing least frequently. In the control group, higher levels of handwashing with soap when compared with baseline may reflect standard WASH training received after baseline data were collected.

While handwashing was noted by participants across intervention arms as being important for reducing disease transmission, handwashing stations (tippy taps) provided in the camp were described as difficult to use, hard to clean, and prone to damage. Such challenges can reduce handwashing practice. Residents highlighted that use of tippy taps was driven largely by a lack of viable alternatives. They also noted that both the height and design of tippy taps were prohibitive for those who were less able and that water would often spill onto people's legs during use. More than half of tippy tap users observed during qualitative observations, principally children and elderly persons, discontinued use after getting wet. Handwashing stations that are difficult to use may discourage habitual handwashing practice. Conversely, improved handwashing technologies may be considered more dignified and also more attractive with additions such as a mirror, and therefore may encourage handwashing with soap [21].

Comparatively speaking, the PPHWK had considerably higher levels of user acceptability and reported use. The new stations were frequently described as being well designed, durable, and easy to use-even for young children and persons with a disability. High levels of user acceptability were associated with high levels of reported (and observed) use. Similar studies have also reported preferences for user-friendly handwashing stations $[1,10]$. In one study, this preference was accompanied by increases in handwashing [10].
Overall, the PPHWK was reported to be easier to use and maintain, and more attractive, motivating, and durable than the standard handwashing stations available in the camp. However, although most PPHWKs were observed to be in good condition, at least 2 (1 in the PPHWK only intervention arm and 1 in the PPHWK+MMH arm) were not. It will be important to determine what factors influence care for the kits (e.g. community buy-in, availability of water or soap, challenges with use, damage, etc.) and establish guidelines for installation and community maintenance. In at least 1 village where PPHWKs were not maintained, residents did not engage in handwashing. This highlights the importance of maintaining kits to facilitate handwashing practice.

Mum's Magic Hands, designed to use nurture and affiliation as emotive drivers to encourage handwashing with soap, was considered effective by all participants in the training or those whose family members, most often mothers and wives, had done the training. Activities and handwashing nudges such as visuals were referenced as positive reminders for handwashing with soap. Subsequent to MMH training, participants reported a number of changes in handwashing practice. Mothers reportedly increased handwashing with soap at key times. They also reported that handwashing with soap increased in their households overall, particularly among children. These findings support structured observation data. Households who received MMH training were less likely to report handwashing with water only and were frequently observed handwashing with soap. Only households receiving MMH had significantly lower levels of reported diarrhea at endline.

\section{Conclusion}

Better handwashing technologies have the potential to increase handwashing practice when paired with effective promotion strategies. Identifying promotion strategies that use emotive drivers may improve both short-term and long-term handwashing with soap practice.

In emergency settings, the lack of a standardized, quickly assembled, readily available, self-contained handwashing kit constitutes a key failure to provide safe, healthy sanitation and hygiene for displaced people. Handwashing with soap is an important measure for reducing disease transmission in refugee contexts. Handwashing technologies and their related characteristics can play an important role in promoting or discouraging handwashing practice. Existing solutions can be messy and difficult to use, particu- 
larly for persons with physical disability, and may ultimately leave individuals at increased risk of illness and death.

In the current study, use of the PPHWK was associated with increased handwashing knowledge and practice, even when used with only a standard hygiene promotion strategy and not MMH. Those with access were less likely to report handwashing with water only, more likely to note proper handwashing techniques at key times, and more frequently observed engaging in handwashing with soap and handwashing in general. Moreover, when the PPHWK was paired with MMH, a stepwise increase was noted. Simply having access to the new handwashing station only improved handwashing knowledge and practice. However, having access to both the new station and an innovative promotion campaign increased handwashing knowledge and practice while reducing self-reported diarrhea. Thus, in addition to the provision of soap and water, this research suggests that effectively pairing new approaches for technology and promotion may significantly improve handwashing practice and subsequently reduce related morbidity among refugee populations.

As stakeholders work to improve WASH-related health outcomes in emergency settings, new approaches to the provision of handwashing facilities and WASH promotion strategies must be considered. Increasing the availability of soap and increasing access to standard WASH promotion strategies is not enough. There is a need to explore the impact and user acceptability of technologies like the Promotion and Practice Handwashing Kit (PPHWK) and handwashing promotion strategies like Mum's Magic Hands $(\mathrm{MMH})$ for improving health in refugee settings. The evaluation findings have also contributed to the further development of PPHWK prototypes. The latest prototype now has theft-resistant mirrors and an integral chamber for liquid soap in the water tank, and the kit can be set up in just 6 minutes.

\section{Acknowledgements}

Our appreciation goes to the following team members for their contributions to the design and implementation of the project: Andy Bastable; Justin Hartree; Lucy Polson; Marion 0’Reilly; Jenny Lamb; Abigail Connolly from Oxfam, Oxford; Jordan Lam and Magdalen Nandawula from Oxfam Tanzania; Matthew White, lead designer from Spark Product Creation; John Stevens and Joel Trotter from the Royal College of Art, and Carl Dolby from Dunster House manufacturing company. Thanks also to Cecilie Hestbæk from HIF for her constant advisory support.

\section{Funding}

The project was supported by Elrha's Humanitarian Innovation Fund (HIF), which in turn was funded by aid from the UK Government.

\section{Bibliography}

1. Hulland RS., et al. "Designing a handwashing station for infrastructure-restricted communities in Bangladesh using the integrated behavioral model for water, sanitation and hygiene interventions (IBM-WASH)". BMC Public Health 13 (2013): $877 \mathrm{~K}$.

2. Hershey CL., et al. "Incidence and risk factors for malaria, pneumonia and diarrhea in children under 5 in UNHCR refugee camps: A retrospective study". Conflict and Health 5.1 (2011): 24 .

3. Peterson E., et al. "The effect of soap distribution on diarrhoea: Nyamithuthu refugee camp". International Journal of Epidemiology 27 (1998): 520.

4. Veerapu N., et al. "Promotion of sanitation and hygiene in a rural area of South India: A community-based study". Journal of Family Medicine and Primary Care 5 (2016): 587-592.

5. Mahamud AS., et al. "Epidemic cholera in Kakuma Refugee Camp, Kenya, 2009: the importance of sanitation and soap". Journal of Infection in Developing Countries 6.3 (2012): 234241.

6. Aiello AE., et al. "Effect of hand hygiene on infectious disease risk in the community setting: a meta-analysis". American Journal of Public Health 98.8 (2008): 1372-1381.

7. Freeman M., et al. "Systematic Review: Hygiene and health: systematic review of handwashing practices worldwide and update of health effects". Tropical Medicine and International Health 19.8 (2014): 906-916.

8. Curtis V and Cairncross S. "Effect of washing hands with soap on diarrhoea risk in the community: a systematic review". The Lancet Infectious Diseases 3.5 (2003): 275-281.

9. Cairncross S., et al. "Water, sanitation and hygiene for the prevention of diarrhea". International Journal of Epidemiology 39 (2010): i193-205.

10. Jenkins MW., et al. "Opportunities to improve domestic hygiene practices through new enabling products: A study of handwashing practices and equipment in rural Cambodia". International Health 5.4 (2013): 295-301. 
11. Biran A., et al. "Hygiene and sanitation practices amongst residents of three long-term refugee camps in Thailand, Ethiopia and Kenya". Tropical Medicine and International Health 17.9 (2012): 1133-1141.

12. Biran AP., et al. "Effect of a behaviour-change intervention on handwashing with soap in India (SuperAmma): a cluster-randomised trial". Lancet Global Health 2.3 (2014): E145-E154.

13. Phillips RM., et al. "Soap is not enough: handwashing practices and knowledge in refugee camps, Maban County, South Sudan". Conflict and Health 9.39 (2015): 1-8.

14. Greenland K., et al. "Multiple behaviour change intervention for diarrhoea control in Lusaka, Zambia: a cluster randomised trial". The Lancet Global Health 4 (2016): e966-e977.

15. Greenland K., et al. "Disentangling the effects of a multiple behaviour change intervention for diarrhoea control in Zambia: a theory-based process evaluation". Globalization and Health 13.1 (2017): 78.

16. Rutter D and Quine L. "Social cognition models and changing health behaviours". In: Rutter D, Quine L, eds. Changing Health Behaviour. Buckingham: Open University Press (2002): 1-27.

17. Curtis V., et al. "Evidence of behaviour change following a hygiene promotion programme in Burkina Faso". Bulletin of the World Health Organization 79.6 (2001): 518.

18. UNHCR Tanzania. Nduta Refugee Camp Situation 3RP Key Indicators Monitoring (2017).

19. Sagan S and Tolani F. "Using emotional and health motivators to promote handwashing with soap among mothers: Pilot of Mum's Magic Hands in Nepal post-earthquake emergency". Oxfam report. October (2016).

20. UNHCR. Burundian Refugee Voluntary Repatriation Operation (2018).

21. Vujcic J., et al. "Handwashing promotion in humanitarian emergencies: strategies and challenges according to experts". Journal of Water, Sanitation, and Hygiene for Development 5.4 (2015): 574-585.

\section{Assets from publication with us}

- Prompt Acknowledgement after receiving the article

- Thorough Double blinded peer review

- Rapid Publication

- Issue of Publication Certificate

- High visibility of your Published work

Website: www.actascientific.com/

Submit Article: www.actascientific.com/submission.php

Email us: editor@actascientific.com

Contact us: +919182824667 